\title{
Recurrent Extraskeletal Myxoid Chondrosarcoma
}

National Cancer Institute

\section{Source}

National Cancer Institute. Recurrent Extraskeletal Myxoid Chondrosarcoma. NCI

Thesaurus. Code C8807.

Reemergence of extraskeletal myxoid chondrosarcoma after a period of remission 